\title{
On the Heat Flux Vector and Thermal Conductivity of Slags: A Brief Review
}

\author{
Mehrdad Massoudi ${ }^{1, *}$, Jeongho Kim ${ }^{2}$ and Ping Wang ${ }^{1}$ \\ Received: 27 July 2015; Accepted: 30 December 2015; Published: 6 January 2016 \\ Academic Editor: Enrico Sciubba \\ 1 U.S. Department of Energy (DOE), National Energy Technology Laboratory (NETL), \\ 626 Cochrans Mill Road, P.O. Box 10940, Pittsburgh, PA 15236, USA; ping.wang@netl.doe.gov \\ 2 Department of Mechanical Engineering, Kyung Hee University, Yong-in, Kyunggi-do 446-701, Korea; \\ kim.enoch@gmail.com \\ * Correspondence: mehrdad.massoudi@netl.doe.gov; Tel.: +1-412-386-4975; Fax: +1-412-386-5870
}

\begin{abstract}
The viscosity and the thermal conductivity of slag are among two of the most important material properties that need to be studied. In this paper we review the existing theoretical and experimental correlations for the thermal conductivity of slag. However, since, in general, slag behaves as a non-linear fluid, it is the heat flux vector which must be studied. Both explicit and implicit approaches are discussed and suggestions about the form of the heat flux vector and the thermal conductivity and their dependence on shear rate, porosity, deformation, etc. are provided. The discussion of the constitutive modeling of the heat flux vector for slag is from a theoretical perspective.
\end{abstract}

Keywords: thermal conductivity; heat conduction; slag; gasification; non-Newtonian fluids; constitutive relations; coal

\section{Introduction}

Mathematical and physical modeling of complex materials, such as slag, in complex applications, such as gasification, present special challenges to modelers. With the advancement of computational fluid dynamics (CFD) packages, the need for accurately modeling non-linear complex materials has increased. Deposition of ash in certain applications, for example, in fluidized-bed combustion, which is caused by the molten mineral matter. Researchers have suggested two possible mechanisms for this phenomenon [1]: (1) partial melting; and (2) viscous flow sintering. The first situation usually occurs with a partial melt where the temperature is in the range $500-700^{\circ} \mathrm{C}$, which is usually lower than the operating temperatures encountered in most fluidized beds. The second mechanism occurs at temperatures about or higher than $1000{ }^{\circ} \mathrm{C}$, and at these temperatures, the material behaves as a highly viscous and non-linear fluid. At such high temperatures, the standard methods of measuring viscosity or thermal conductivity are not necessarily applicable. For example, for the heat flux vector for porous materials, the Fourier's law of heat conduction is generally used where an effective thermal conductivity is introduced; however, studies have shown that for many complex materials the heat flux vector can depend not only on the temperature gradient, as is the case in the Fourier's law, but also on the shear rate, and other parameters. There are two important concepts to consider: slagging and fouling. While slagging is concerned with the deposition of ash which occurs in the radiative section of a boiler, fouling occurs in the convective-pass region [2]. Vorres et al. [3] observed that in certain applications coal slags generally behave more like a polymeric fluid [4]. As Jak et al. [5] observed, at, the temperature at the wall of a gasifier can be taken to be $\sim 450{ }^{\circ} \mathrm{C}$, while the temperature at the slag surface is $\sim 1450^{\circ} \mathrm{C}$. Such a sharp temperature gradient causes various types of responses including the creation of different sub-layers and can influence the thermal conductivity of the slag. As the operating temperature decreases, the slag cools, and solid crystals begin to form. In such cases, the 
slag layers should be modeled as a non-Newtonian fluid, composed of liquid silicate and crystals. In these situations, a better understanding of the rheological properties of the slag, such as yield stress and shear-thinning, are critical in determining the optimum operating conditions [6]. Groen et al. [6] noticed that at the critical viscosity temperature, $T_{c v}$, the slag changes from a homogeneous fluid to a mixture composed of fluid and a crystallizing phase (solid), where there is an increase in the (apparent) viscosity due to the presence of the crystals or the change in the melt composition.

Under high-temperature and high-pressure conditions, the dynamics and properties of coal particles, such as viscosity and thermal conductivity, change significantly. In order to develop an accurate heat transfer model for coal combustion or gasification at high temperatures, to some extent, the thermal and the rheological properties of ash and slag need to be understood and modeled properly (see $[7,8]$ for a review). Experiments have to be devised to quantify and describe the non-linear behavior of complex materials such as slag, and theories have to be developed to explain experimental observations as well as predict physical phenomena not yet confirmed by experiments. From the continuum mechanics perspective, these transport properties are modeled as constitutive relations.

In this paper, we look at the various approaches to obtain the thermal conductivity of slag. In general, these models are based on experiments. Since the molten slag behaves as a non-linear fluid, we discuss the constitutive modeling of the thermal conductivity and mention that more appropriately, it is the heat flux vector which should be studied. Based on this brief review, constitutive relations are proposed, where the heat flux vector depends on the motion, temperature, and concentration. We first provide the governing equations for the flow of slag if the slag is considered to behave as a single component non-homogeneous and non-linear material. Massoudi and Wang [1,9] discuss cases where slag can be considered to be a multi-component material.

\section{Governing Equations of Motion and Heat Transfer}

If slag is treated as a single component (often called single phase) material, then, in the absence of any electro-magnetic effects, the governing equations of motion are the conservation of mass, linear momentum, convection-diffusion, and energy equations [10]:

Conservation of mass:

$$
\frac{\partial \rho}{\partial t}+\operatorname{div}(\rho \mathrm{v})=0
$$

where $\rho$ is the density of the fluid, $\partial / \partial \mathrm{t}$ is the partial derivative with respect to time, and $\mathbf{v}$ is the velocity vector. For an isochoric motion, we have $\operatorname{div} \mathbf{v}=0$.

Conservation of linear momentum:

$$
\rho \frac{\mathrm{d} \mathbf{v}}{\mathrm{dt}}=\operatorname{div} \mathbf{T}+\rho \mathbf{b}
$$

where $\mathbf{b}$ is the body force vector, $\mathbf{T}$ is the Cauchy stress tensor, and $\mathrm{d} / \mathrm{dt}$ is the total time derivative, given by $\frac{\mathrm{d}(.)}{\mathrm{dt}}=\frac{\partial(.)}{\partial \mathrm{t}}+[\operatorname{grad}().] \mathbf{v}$. The balance of moment of momentum reveals that, in the absence of couple stresses, the stress tensor is symmetric.

Conservation of Concentration:

$$
\frac{\partial \mathrm{c}}{\partial \mathrm{t}}+\operatorname{div}(\mathbf{c v})=\mathrm{f}
$$

where $\mathrm{c}$ is the concentration and $\mathrm{f}$ is a constitutive parameter. This equation is also known as the convection-reaction-diffusion equation. Depending on the application, this equation may not be necessary.

Conservation of Energy:

$$
\rho \frac{\mathrm{d} \varepsilon}{\mathrm{dt}}=\mathbf{T} \cdot \mathbf{L}-\operatorname{div} \mathbf{q}+\rho \mathbf{r}
$$

where $\varepsilon$ is the specific internal energy, $\mathbf{L}$ is the gradient of velocity, $\mathbf{q}$ is the heat flux vector, and $r$ is the radiant heating. Thermodynamical considerations require the application of the second law 
of thermodynamics or the entropy inequality. The local form of the entropy inequality is given by (see Liu [11] p. 130):

$$
\rho \dot{\eta}+\operatorname{div} \varphi-\rho s \geqslant 0
$$

where $\eta(\mathbf{x}, \mathbf{t})$ is the specific entropy density, $\varphi(\mathbf{x}, \mathbf{t})$ is the entropy flux, and $\mathrm{s}$ is the entropy supply density due to external sources, and the dot denotes the material time derivative. If it is assumed that $\varphi=\frac{1}{\theta} \mathbf{q}$, and $\mathrm{s}=\frac{1}{\theta} \mathrm{r}$, where $\theta$ is the absolute temperature, then Equation (2.5) reduces to the Clausius-Duhem inequality:

$$
\rho \dot{\eta}+\operatorname{div} \frac{\mathbf{q}}{\theta}-\rho \frac{\mathrm{r}}{\theta} \geqslant 0
$$

Even though we do not consider the effects of the Clausius-Duhem inequality in this paper, for a complete thermo-mechanical study, the Second Law of Thermodynamics must be considered [11-13]. To achieve "closure" for these equations, in general, we must provide constitutive relations for $\mathbf{T}, \mathbf{q}, \mathrm{f}, \varepsilon$, and $\mathrm{r}$. In certain applications, some of these effects can be ignored. Nevertheless, the constitutive modeling of $\mathbf{T}$ and $\mathbf{q}$ remain a challenge in the problems or industrial applications related to thermofluid mechanics.

In the next section, we discuss some of the approaches taken by different researchers in formulating or obtaining a thermal conductivity model for slag. In general, these models are based on experiments.

\section{A Brief Review of Thermal Conductivity of Slag}

Fourier, in his pioneering book, "Analytical Theory of Heat" published in 1822 [14], proposed a constitutive relationship for the heat flux vector. The Fourier's law of heat conduction, written in modern vector notation is: $\mathbf{q}=-\mathrm{k} \nabla \theta$ where $\mathbf{q}$ is the heat flux vector, $\theta$ is the temperature, $\nabla$ (or grad) denotes the gradient operator, and $\mathrm{k}$ is a material property known as thermal conductivity. For the heat flux vector, for example in porous materials, generally, Fourier's law of heat conduction is used where an effective thermal conductivity is introduced [15]; however, studies have shown that for many complex materials the heat flux vector can depend not only on the temperature gradient, as is the case in Fourier's law, but also on the shear rate, and other parameters [16]. Interestingly, Fourier in his manuscript formulated thermal conductivity as a mathematical concept rather than an experimentally measurable parameter $[17,18]$. There is much information about the thermal conductivity of complex materials such as porous media, polymers, granular materials, etc. In what follows we look at a few cases specifically related to slag.

Russell [19] derived the thermal conductivity for an array of cubes, where:

$$
\mathrm{k}_{\mathrm{eff}} / \mathrm{k}_{\mathrm{c}}=\left[\mathrm{r} \cdot \varphi^{2 / 3}+\left(1-\varphi^{2 / 3}\right)\right] /\left[\mathrm{r} \cdot\left(\varphi^{2 / 3}-\varphi\right)+\left(1-\varphi^{2 / 3}+\varphi\right)\right]
$$

where $k_{c}$ is the thermal conductivity of the continuous phase (particulate), $k_{d}$ is the thermal conductivity of the discrete phase (spherical particles), $r$ is ratio of $k_{d} / k_{c}$, and $\varphi$ the volume fraction of the discrete phase. The cubic parallel series (CPS) model suggested by Leach [20] is the same as that of Russell's model except that the discrete phase is now air bubbles. The thermal conductivity of the CSP model is given by:

$$
\mathrm{k}_{\mathrm{eff}} / \mathrm{k}_{\mathrm{g}}=\mathrm{r} \cdot\left[2-\mathrm{r}+(\mathrm{r}-1) \cdot \varphi^{1 / 3}\right] /\left[1-(\varphi-1) \mathrm{e}^{1 / 3}\right]
$$

where e is the porosity of the material. Similar to the kinetic theory of gases, Kingery [21] suggested that the thermal conductivity $\left(\mathrm{k}_{\mathrm{c}}\right)$ of a slag can be given:

$$
\mathrm{k}_{\mathrm{c}}=1 / 3 \mathrm{c}_{\mathrm{p}} \rho \mathrm{v} \lambda
$$

where $v$ and $\lambda$ are the velocity and the mean free path of a phonon, respectively, $\rho$ is the density and $c_{p}$ is the specific heat capacity of the slag. If $\mathrm{v}$ is constant, then the thermal conductivity decreases with 
increasing temperature since $\rho$ decreases, or $c_{p}$ increases with increasing the temperature, resulting in a nearly constant product. Furthermore, increasing the temperature causes a decrease in $\lambda$.

Parker et al. [22] developed the laser flash method to measure thermal diffusivity of a multi-layered material where the thermal diffusivity $(\alpha)$ is obtained from the following relationship:

$$
\alpha=0.1388 \delta^{2} / t_{1 / 2}
$$

where $\delta$ is the thickness of the sample, and $t_{1 / 2}$ is the time to the half maximum.

Brailsford and Major [23] suggested a new correlation for the thermal conductivity of a random mixture of solid and gas (continuous) phases as:

$$
\mathrm{k}_{\text {eff }} / \mathrm{k}_{2}=\left[\mathrm{a}+\left(\mathrm{a}^{2}+8 \mathrm{k}_{1} / \mathrm{k}_{2}\right)^{0.5}\right] / 4.0
$$

where $a$ is defined as $\left(3 \varphi_{1}-1\right)\left(k_{1} / k_{2}\right)+\left(3 \varphi_{2}-1\right), \varphi_{1}$ and $\varphi_{2}$ are the volume fractions of fluid and solid phases, respectively, and $k_{1}$ and $k_{2}$ are the thermal conductivities of each phase, respectively, which can be calculated using Rayleigh's correlation.

The thermal conductivity of slags has scarcely been measured in the heat transfer applications involving metal processing. Susa et al. [24] measured the thermal conductivity of slags using the hot wire method. They presented an empirical formula for the thermal conductivity of $\mathrm{CaO}-\mathrm{SiO}_{2}-\mathrm{Al}_{2} \mathrm{O}_{3}$ type slags within the temperature range of $1100{ }^{\circ} \mathrm{C}-1500{ }^{\circ} \mathrm{C}$ and $\mathrm{Na}_{2} \mathrm{O}-\mathrm{SiO}_{2}$ type slags in the temperature range of $800^{\circ} \mathrm{C}-1300{ }^{\circ} \mathrm{C}$, respectively expressed as:

$$
\mathrm{k}=-\mathrm{a}+\left(\mathrm{b} \times 10^{3}\right) / \theta
$$

where $\theta$ is the absolute temperature, a is between $1.5-3.5$, and $b$ is in the range of 3-7.

Taylor and Mills [25] measured thermal diffusivities of six slags $\left(\mathrm{CaF}_{2}-\mathrm{Al}_{2} \mathrm{O}_{3}-\mathrm{CaO}\right.$ system $)$ used in the electroslag remelting (ESR) in the temperature ranges of $200-1200{ }^{\circ} \mathrm{C}$ using the laser flash technique. Thermal conductivity $\mathrm{k}$ was defined using the thermal diffusivity $\alpha$ as shown below:

$$
\mathrm{k}=\alpha \mathrm{c}_{\mathrm{p}} \rho
$$

where $c_{p}$ and $\rho$ are the specific heat capacity and the density of the material, respectively. They also presented the thermal diffusivities and the thermal conductivities of six slags. The total or the effective thermal conductivity, $\mathrm{k}_{\mathrm{eff}}$, consisting of contributions from the phonon thermal conductivity $\mathrm{k}_{\mathrm{c}}$ and the radiation conductivity $k_{R}$, was given by the following equation:

$$
\mathrm{k}_{\mathrm{eff}}=\mathrm{k}_{\mathrm{c}}+\mathrm{k}_{\mathrm{R}}
$$

One of the main concerns in the measurement of the thermal conductivity of semi-transparent media is how to determine the contribution of $k_{R}$. When the specimen is optically thick, $k_{R}$ can be calculated by the following equation:

$$
\mathrm{k}_{\mathrm{R}}=\frac{16 \sigma \mathrm{n}^{2} \theta^{3}}{3 \bar{\alpha}}
$$

where $\sigma$ is the Stefan-Boltzmann constant, $\mathrm{n}$ the refractive index, $\bar{\alpha}$ the mean absorption coefficient, and $\theta$ is the thermodynamic temperature. It is observed that $k_{R}$ becomes dominant at higher temperatures. The radiation conduction is shown to be negligible, but phonon conduction occurs predominantly in the polycrystalline specimens. An appreciable contribution to the thermal conductivity originates from gaseous conduction through pores and microcracks in the specimen. The thermal conductivities of $\mathrm{CaF}_{2}-\mathrm{Al}_{2} \mathrm{O}_{3}-\mathrm{CaO}$ system were observed to decrease with decreasing $\mathrm{CaF}_{2}$ content.

Mills [26] suggested that the total (or the effective) thermal conductivity ( $\left.k_{\text {eff }}\right)$ consists of three contributions (i) the thermal (or phonon) conductivity $\left(\mathrm{k}_{\mathrm{c}}\right)$; (ii) radiation conductivity $\left(\mathrm{k}_{\mathrm{R}}\right)$ and (iii) electronic conductivity $\left(\mathrm{k}_{\mathrm{el}}\right)$. A low-density, highly-porous material will have a low thermal 
conductivity. The thermal conductivity of glasses or slags were found to depend on the thickness of the specimens. Optically thick slag is usually considered to occur when $\bar{\alpha} \delta>3.5$ where $\bar{\alpha}$ and $\delta$ are the absorption coefficient and the thickness of the slag, respectively. The radiation conductivity cannot easily be obtained for optically thin slags $(\bar{\alpha} \delta<3.5)$ and for unsteady state processes. For an optically thick sample, $\mathrm{k}_{\mathrm{R}}$ and $d$ decrease with increasing $\bar{\alpha}$. The average absorption coefficient, $\alpha_{\mathrm{m}}$, can be influenced by the temperature. The contribution of electronic conductivity has been widely ignored since little is known of electronic conduction mechanism associated with the heat transfer in slags. One widely-used model of the heat transfer is the diffusion approximation where the heat flux $(q)$ is defined as:

$$
\mathrm{q}=-\mathrm{k}_{\mathrm{eff}}(\mathrm{d} \theta / \mathrm{dy})
$$

where $k_{\text {eff }}\left(=k_{c}+k_{R}\right)$ is the effective thermal conductivity. This model is valid for small $k_{R}$ and when $\bar{\alpha} d>8$ [26]. Fine et al. [27] determined the total thermal diffusivity $\left(\alpha_{\text {eff }}\right)$ of solid and liquid slags containing $0 \%$ to $25 \% \mathrm{FeO}$ using the radial wave method, where:

$$
\alpha_{\text {eff }}=10^{-7}(1.5-0.5 \mathrm{~B})+1.8 \times 10^{-6} \frac{(\theta / 1500)^{3}}{(\% \mathrm{FeO})^{0.8}} \mathrm{~m}^{2} \mathrm{~s}^{-1}
$$

where $B$ represents the $\mathrm{CaO} / \mathrm{SiO}_{2}$ ratio and $\theta$ is the temperature with the unit of ${ }^{\circ} \mathrm{C}$. This equation shows that $\alpha_{\text {eff }}$ decreases with an increase in the $\mathrm{FeO}$ content. Odawara et al. [28] used the differential three layered method and the Front-heating detection method are the laser flash methods for the measurement of thermal properties of the silicate melts at high temperatures.

Chekhovskoi and Ulashchik [29] developed a cell technique to measure the thermal conductivity of melts of coal and dielectric slags by the radial heat flow method. The thermal conductivity of the slag was calculated using the following equation:

$$
\mathrm{k}_{\text {eff }}=\frac{\mathrm{Ui}}{2 \pi \mathrm{L}} \frac{\ln \mathrm{d}_{2}-\ln \mathrm{d}_{1}}{\theta_{1}-\theta_{2}}
$$

where $\mathrm{U}$ is the voltage drop in the work area length, $i$ is the current flowing through the tube, and $\mathrm{L}$ is the distance between the discs, $\mathrm{d}_{1}$ and $\mathrm{d}_{2}$ are the inside diameter and the outer diameter, respectively. It appears that the effective thermal conductivity of the slag can be thought to be composed of various contributions and can be given by the following equation [29]:

$$
\mathrm{k}_{\mathrm{eff}}=\mathrm{k}_{\mathrm{c}}+\mathrm{k}_{\mathrm{R}}+\mathrm{k}_{\mathrm{cov}}+\mathrm{k}_{\mathrm{el}}
$$

where $\mathrm{k}_{\mathrm{c}}$ is the phonon thermal component, $\mathrm{k}_{\mathrm{R}}$ is the radiative component, $\mathrm{k}_{\mathrm{cov}}$ is the convective component, and $\mathrm{k}_{\mathrm{el}}$ is the electronic component of the thermal conductivity. The convective component can be ignored where $\mathrm{Pr} \mathrm{Gr}<10^{3}$ where $\mathrm{Pr}$ and $\mathrm{Gr}$ are the Prandtl and the Grashof numbers, respectively. According to Chekhovskoi and Ulashchik [29], the radiative component of the thermal conductivity can be calculated using the Rosseland equation:

$$
\mathrm{k}_{\mathrm{R}}=\frac{16}{3} \frac{\mathrm{n}^{2}}{\bar{\alpha}} \sigma \theta^{3}
$$

where $\mathrm{n}$ is the mean refractive index, $\sigma$ the Stefan-Boltzmann constant, and $\bar{\alpha}$ the mean absorption coefficient. Therefore, in a sense, the effective thermal conductivity of a slag can be represented, in a more compact form, as the sum of the thermal (or phonon) conductivity $\left(\mathrm{k}_{\mathrm{c}}\right)$ and radiation conductivity $\left(\mathrm{k}_{\mathrm{R}}\right)$ :

$$
\mathrm{k}_{\text {eff }}=\mathrm{k}_{\mathrm{c}}+\mathrm{k}_{\mathrm{R}}=\mathrm{A}+\mathrm{B} \theta^{3}
$$

where $\mathrm{A}$ and $\mathrm{B}$ are appropriate constants including material parameters. 
Botterill et al. [30] reviewed a number of models and compared the predictions. They suggested the following formula:

$$
\mathrm{k}_{\mathrm{r}}=4 \sigma \chi \mathrm{d} \theta^{3}
$$

where $\sigma$ is the Stefan-Boltzmann constant, $\chi$ is an exchange factor that includes the effect of particle diameter and emissivity of the particles, and $\mathrm{d}$ is the particle diameter.

In general, the equation governing the heat transfer in slags is:

$$
\rho c_{\mathrm{p}} \frac{\partial \theta}{\partial \mathrm{t}}+\operatorname{div}\left(\mathbf{q}_{\mathrm{c}}+\mathbf{q}_{\mathrm{R}}\right)=\mathrm{q}_{\mathrm{m}}
$$

where $\rho$ is the density, $c_{p}$ the specific heat, $\mathbf{q}_{\mathrm{c}}$ and $\mathbf{q}_{\mathrm{R}}$ the heat fluxes due to conduction and radiation, respectively, and $\mathrm{q}_{\mathrm{m}}$ the volumetric rate of heat generation. The heat flux due to conduction and radiation are given by Mikrovas and Argyropoulos [31]:

$$
\begin{gathered}
\operatorname{div} \mathbf{q}_{\mathrm{c}}=\operatorname{div}\left(-\mathrm{k}_{\mathrm{c}} \nabla \theta\right) \\
\operatorname{div} \mathbf{q}_{\mathrm{R}}=\int_{\lambda=0}^{\infty} \alpha_{\lambda}\left[4 \mathrm{e}_{\beta \lambda}(\lambda, \theta)-\int_{0}^{4 \pi} \mathrm{i}_{\lambda}(\lambda, \omega) \mathrm{d} \omega\right] \mathrm{d} \lambda
\end{gathered}
$$

where $\alpha_{\lambda}$ is the monochromatic absorption coefficient, $\lambda$ the wavelength, $\mathrm{e}_{\beta \lambda}$ the monochromatic black body emissive power, $i_{\lambda}$ the directional monochromatic intensity, and $\omega$ the solid angle. At steady state condition and with no heat generation, Equation (3.17) becomes:

$$
\operatorname{div}\left(\mathbf{q}_{\mathrm{c}}+\mathbf{q}_{\mathrm{R}}\right)=0
$$

For an optically-thick sample, the radiation heat flux is given by:

$$
\mathbf{q}_{\mathrm{R}}=-\frac{4 \mathrm{n}^{2} \sigma \nabla\left(\theta^{4}\right)}{3 \bar{\alpha}}
$$

where $\mathrm{n}$ is the refractive index, $\sigma$ the Stefan-Boltzmann constant, and $\bar{\alpha}$ the mean absorption coefficient. For small temperature gradients, the radiation heat flux can be approximated as:

$$
\mathbf{q}_{\mathrm{R}}=-\mathrm{k}_{\mathrm{R}} \nabla \theta
$$

where the radiation conductivity, $\mathrm{k}_{\mathrm{R}}$, is defined by:

$$
\mathrm{k}_{\mathrm{R}}=-\frac{16 \eta^{2} \sigma \theta^{3}}{3 \bar{\alpha}}
$$

Applying Equations (3.18) and (3.22) to (3.20) yields:

$$
\operatorname{div}\left(-\mathrm{k}_{\mathrm{c}} \nabla \theta-\mathrm{k}_{\mathrm{R}} \nabla \theta\right)=\operatorname{div}\left(-\mathrm{k}_{\mathrm{eff}} \nabla \theta\right)=0
$$

Susa et al. [32] used the hot strip method to measure the thermal conductivity $(\mathrm{k})$, thermal diffusivity $(\alpha)$, and specific heat $\left(c_{\mathrm{p}}\right)$ of $\mathrm{Fe}_{2} \mathrm{O}_{3}-\mathrm{SiO}_{2}-\mathrm{CaO}$ synthetic slags over a wide temperature range (300-1600 K). They presented two approximate equations for the short time (less than about $1 \mathrm{~s}$ ) and long time (greater than $1 \mathrm{~s}$ ) regions, respectively:

$$
\begin{gathered}
\mathrm{k} / \alpha^{1 / 2}=\frac{\mathrm{Q} / 2 \mathrm{w} \pi^{1 / 2}}{\mathrm{~d}(\Delta \theta) \mathrm{d}\left(\mathrm{t}^{1 / 2}\right)} \\
\mathrm{k}=\frac{\mathrm{Q} / 4 \pi}{\mathrm{d}(\Delta \theta) / \mathrm{d}(\ln \mathrm{t})}
\end{gathered}
$$


where $\Delta \theta$ is the temperature increase, $Q$ the heat generation rate per unit length of the heater, $2 w$ the width of the heater, and $t$ time. Thermal diffusivity can be determined from Equation (3.25) and Equation (3.26). Therefore, specific heat is calculated from $c_{p}=k / \alpha \rho$ where $\rho$ is the density of the material. On the other hand, radiation conductivity can be estimated by the following equation:

$$
\mathrm{k}_{\mathrm{R}}=\frac{16}{3} \frac{\mathrm{n}^{2}}{\alpha} \sigma \theta^{3}
$$

where $\mathrm{n}$ is the mean refractive index of slags, $\sigma$ the Stefan-Boltzmann constant, and $\bar{\alpha}$ the absorption coefficient. The refractive index can be determined from the following empirical equation [33]:

$$
(\mathrm{n}-1) / \rho=\sum \mathrm{N}_{\mathrm{i}} \mathrm{W}_{\mathrm{i}} / 100
$$

where $\mathrm{N}_{\mathrm{i}}$ is the specific refractive index of substance $i$ and $\mathrm{W}_{\mathrm{i}}$ is the weight percentage of substance $i$.

A number of review articles presented the thermal conductivity of porous or particulate materials [30,34-36]. The simplest models for estimating the effective thermal conductivity of porous materials are given by the following equations if the heat transfer is in the direction parallel or normal to the layers of solid and gas, respectively [37]:

$$
\begin{gathered}
\mathrm{k}_{\mathrm{eff}} / \mathrm{k}_{\mathrm{g}}=\varphi+(1-\varphi) \cdot \mathrm{k}_{\mathrm{s}} / \mathrm{k}_{\mathrm{g}} \\
\mathrm{k}_{\text {eff }} / \mathrm{k}_{\mathrm{g}}=1 /\left[\varphi+(1-\varphi) / \mathrm{k}_{\mathrm{s}} / \mathrm{k}_{\mathrm{g}}\right]
\end{gathered}
$$

where $k_{\text {eff }}$ is the effective thermal conductivity, $k_{s}$ the thermal conductivity of the solid phase, $\mathrm{k}_{\mathrm{g}}$ the thermal conductivity of the gas phase, and $\varphi$ the porosity of the material. The effective thermal conductivity is higher when the direction of the heat transfer is parallel to the layers.

A theoretical equation for the effective thermal conductivity was suggested for a cubic array of uniform spheres with a maximum porosity of $\pi / 6$ [37]:

$$
\mathrm{k}_{\mathrm{eff}} / \mathrm{k}_{\mathrm{c}}=[(2+\mathrm{r}) /(1-\mathrm{r})-2 \varphi] /[(2+\mathrm{r}) /(1-\mathrm{r})+\varphi]
$$

Gupta, Wall and Baxter [37] reviewed the effect of the radiation on the effective thermal conductivity. McAdams [38] proposed the following formula for the radiation contribution in a packed bed:

$$
\mathrm{k}_{\mathrm{r}}=0.00692 \varepsilon \mathrm{d} \cdot(\theta / 100)^{3}
$$

In the above equation, $\varepsilon$ is the emissivity, and $\mathrm{d}$ is the particle diameter. The emissivity of the particles is not considered. Laubitz [39] measured $\mathrm{k}_{\mathrm{e}}$ for several powders and determined the radiative conductivity as a function of particle diameter $(d)$, its emissivity $(\varepsilon)$ and the porosity $(\varphi)$ where:

$$
\mathrm{k}_{\mathrm{r}}=4 \varepsilon \sigma \theta^{3}(\mathrm{~d} / \varphi)\left(1-\varphi^{2 / 3}+\varphi^{4 / 3}\right)
$$

Rezaei et al. [40] calculated the thermal conductivity of the coal ash using the following equation:

$$
\mathrm{k}_{\text {ash }}=\mathrm{k}_{\text {ref }} \frac{\mathrm{S}_{\text {ref }}}{\mathrm{S}_{\text {ash }}} \frac{\left(\frac{\Delta \theta}{\mathrm{x}}\right)_{\text {ref }}}{\left(\frac{\Delta \theta}{\mathrm{x}}\right)_{\text {ash }}}
$$

where $k_{\text {ash }}$ is the thermal conductivity of the coal ash, $k_{\text {ref }}$ is the thermal conductivity of the reference material, $S_{\text {ash }}$ is the surface area of the coal ash, $S_{\text {ref }}$ is the surface area of the reference material, $\mathrm{x}_{\text {ash }}$ is the length of the ash pellet, and $\mathrm{x}_{\mathrm{ref}}$ is the length of the reference material. Their results show that increasing the temperature or decreasing the porosity causes an increase in the thermal conductivity of coal ash due to an increased contact between the particles. It was observed that 
there is a difference in thermal conductivity between the heating and the cooling cycles, which can be attributed to better contact between particles. Increasing the particle size causes higher thermal conductivity as confirmed by the results of Boow and Goard [41]. Also, by increasing the sintering temperature or the time, the thermal conductivity of the ash samples has a higher value.

Quested and Monaghan [42] determined the thermal conductivity of molten slags and fluxes using the line source method (or the transient hot wire method) by using the following equation:

$$
\Delta \theta=\frac{\mathrm{q}}{4 \pi \lambda} \ln \left(\frac{4 \alpha \mathrm{t}}{\mathrm{r}_{0}{ }^{2} \exp \gamma}\right)
$$

where $\mathrm{q}$ is the heat input per unit length of wire, $\mathrm{r}$ the radius of the wire, $\alpha$ the thermal diffusivity of the liquid, and $\mathrm{t}$ time. This equation is valid when $\left(\mathrm{r}^{2} / 4 \alpha \mathrm{t}\right)<<1$. The thermal conductivity can be determined from a plot of $\Delta \theta$ as a function of $\ln t$. This measurement takes about $1 \mathrm{sec}$ which minimizes the onset of convection on the heat transfer measurement. However, this measurement is not robust due to sensitivity of electrode end effect errors and wire contamination by the sample.

Kang and Morita [43] measured the thermal conductivity of silicate melts using non-stationary hot wire method (see Equation (3.26)). Sun et al. [44] measured the thermal conductivity of the slag sample using the same equation as Kang and Morita [43]. Susa et al. [45] measured the thermal conductivity of $\mathrm{CaO}-\mathrm{SiO}_{2}-\mathrm{Al}_{2} \mathrm{O}_{3}$ glassy slags using the non-stationary hot wire method, where:

$$
\Delta \theta=\frac{\mathrm{Q}}{4 \pi \mathrm{k}}(\ln \mathrm{t}+\mathrm{A})
$$

where $\mathrm{Q}$ is the heat generation rate per unit length of the wire, $\mathrm{t}$ is the time, and $\mathrm{A}$ is a constant. The thermal conductivity of the sample can be expressed in Equation (3.26) using the plot of $\Delta \theta$ as a function of lnt. Ni et al. [46] developed a slag flow model for two kinds of coal gasification cases in order to simulate the slag flow and the phase transformation. They adopted the slag viscosity proposed by Bird et al. [47] as follows:

$$
\mu(\mathrm{x})=\mu(0) \mathrm{e}^{-\ln \left(\frac{\mu\left(\delta_{1}\right)}{\mu(0)}\right)\left(\mathrm{x} / \delta_{1}\right)}
$$

where $\mu(0)$ is the viscosity at the slag surface at distance $x=0$ and $\mu\left(\delta_{1}\right)$ is the viscosity at the critical viscosity temperature $\left(\theta_{\mathrm{cv}}\right)$ at distance $\mathrm{x}=\delta_{1}$ where $\delta_{1}$ is the thickness of the liquid slag. The slag density suggested by Mills and Rhine [48] was used, where the weight percentages of the slag components is:

$$
\rho_{\mathrm{s}}=2460+18\left(\mathrm{FeO}+\mathrm{Fe}_{2} \mathrm{O}_{3}+\mathrm{MnO}\right)\left(\mathrm{kg} \mathrm{m}^{-3}\right)
$$

They approximate the slag heat capacity $c_{p s}$ as the simple sum of the partial mole fraction and the molar heat capacity:

$$
c_{p s}=p_{1} c_{p 1}+p_{2} c_{p 2}+p_{3} c_{p}+\cdots
$$

where $p_{i}$ is the mole fraction and $c_{p}$ is the partial molar heat capacity. The effective thermal conductivity $\mathrm{k}_{\text {eff }}$ of the liquid slag can be calculated:

$$
\mathrm{k}_{\text {eff }}=\alpha_{\text {eff }} \rho_{\mathrm{s}} \mathrm{c}_{\mathrm{ps}}
$$

where the effective thermal diffusivity $\alpha_{\text {eff }}$ is $4.5 \times 10^{-7}\left(\mathrm{~m}^{2} / \mathrm{s}\right)$ and $\rho_{\mathrm{s}}$ and $\mathrm{c}_{\mathrm{ps}}$ are determined from Equations (3.39) and (3.40), respectively. Brackbill et al. [49] used the volume of the fluid model and the continuum surface force model for the slag surface tension to find the free surface of the slag flow using the CFD approach. Hasegawa et al. [50] reviewed the measurement techniques for the thermal conductivity of molten silicate at high temperatures. 
In summary, measurement techniques for the thermal conductivity and thermal diffusivity of slags can be described as follows:

- Thermal conductivity of coal ashes and slags of different porosity with a cubicle array of uniform cubes or cubic cells stacked together can be calculated using Equation (3.1) or Equation (3.2).

- Thermal diffusivity of different materials over a broad temperature range can be measured using Equation (3.4).

- Solid and liquid slags are placed in a cylindrical crucible in the isothermal zone of a furnace and their thermal diffusivity can be measured using Equation (3.11).

- The radial heat flow method with cylindrical geometry and a centered heating element can be used to determine the steady state thermal conductivity of slags using Equation (3.12).

- The hot-wire method is a transient radial flow method to calculate thermal conductivity measurements of slags using Equation (3.26)

- The line source method as a transient technique can be used to determine the thermal conductivity of molten slags using Equation (3.36).

Or, alternatively, as suggested by one of the anonymous reviewers (to whom we are grateful), we could present a summary of the results in the following manner:

- There are cases where the slag is considered as a single-phase material [10], as an array of cubes [19] or the parallel cubic series with the discrete phase of air bubbles [20], or a random mixture of solid and gas (continuous) phases [23].

- There are the cases where models are developed using different parameters, for example where the effects of porosity [20], or the density with the specific heat capacity of the slag [22] are considered, where in some cases the thickness of the sample and its transparency $[25,26]$ are also included. Certain studies consider the effect of particle diameter and emissivity [30], time [32], and in some complicated situations, even the effects of the anisotropy of the heat transfer in different directions (parallel or normal to the layers) [37] are presented. Other researchers, have studied the effect of radiation heat transfer [37,38], or included the surface area of slag [40] and the contacts between the particles, whereas some studies have considered the slag viscosity [46] and the surface tension effects [49].

- There also models which evaluate different components of the thermal conductivity, for example, the phonon thermal conductivity [25], the phonon component along with the radiative, convective and electronic components [29].

- And finally, there models based specifically on the different methods for measurement of the thermal conductivity; these are shown in Table 1.

Table 1. Measurement techniques for the thermal conductivity and thermal diffusivity of slags.

\begin{tabular}{cc}
\hline Prediction of Thermal Conductivity of Ash Deposits & See Equations (3.1) and (3.2) \\
\hline The laser flash method & See Equation (3.4) \\
The radial wave method & See Equation (3.11) \\
The radial heat flow method & See Equation (3.12) \\
The hot wire method & See Equation (3.26) \\
The line source method & See Equations (3.35) \\
\hline
\end{tabular}

In the next section, we discuss various existing constitutive models for non-linear elastic and viscous materials that can be used to model the thermal characteristics of slag.

\section{Constitutive Modeling of the Heat Flux Vector for Molten Slag}

As evidenced in Section 3 of this paper, the thermal conductivity of slag is one of the most important parameters in determining the heat transfer characteristics and the proper operating conditions for 
a gasifier. However, thermal conductivity is only one of the important parameters and since slag, in general, behaves as a non-linear viscoelastic fluid, we must study the constitutive modeling of the heat flux vector for slag. That is, if we know how the slag thermal conductivity changes as a function of temperature, concentration, shear rate, etc., we still do not know much about the complete thermal characteristics or behavior of the slag.

A constitutive relation is an equation which relates the unknowns, such as the stress tensor $\mathbf{T}$ or the heat flux vector $\mathbf{q}$ to other quantities such as velocity, displacement, temperature, etc., which are the actual quantities that are to be solved in the governing equations, or can be measured experimentally. If the unknown quantities, for example $\mathbf{T}$ or $\mathbf{q}$ are explicitly related to the kinematical (velocity, or displacement) or thermal (temperature) quantities, then that constitutive relation is known as an explicit constitutive relation. In general, for example, in the explicit scheme, we start with equations such as: $\mathbf{q}=\mathbf{q}(\theta, \operatorname{grad} \theta, \ldots)$ where $\theta$ is the temperature. The selection of the dependent variables, i.e., the arguments in the function, is based on previous experience, if any, intuition or insight, and perhaps experimental observation. For the heat flux vector for an isotropic elastic material or a viscous fluid, the most common expression is the Fourier's law of conduction $\mathbf{q}=-\mathrm{k} \operatorname{grad} \theta$, where $\mathrm{k}$ is known as the thermal conductivity of the material.

If, however, it is not possible to directly relate the unknowns to the knowable (or measurable) quantities, then we need to derive or obtain an implicit constitutive relation. Amongst the early examples of implicit constitutive relations in modern continuum mechanics one can name Maxwell's fluid models or Oldroyd's fluid [51,52] models and Truesdell's hypoelastic [53,54] model. Rajagopal [55] has provided a general scheme for deriving implicit relations for the stress tensor of a fluid. Similarly, in a general way, the heat flux vector can be given as an implicit function of the temperature gradient, $\nabla \theta$ in the form [56,57]: $\mathbf{g}(\mathbf{q}, \nabla \theta, \theta)=0$ Clearly, from an analytical or computational perspective, explicit constitutive equations are preferred as they are much easier to deal with; however, from a practical point of view, there are many materials, such as viscoelastic fluid with a relaxation time, whose response characteristics require an implicit model.

The basic thought experiment motivating the formulation of the constitutive relation is this: Slag is not a "solid block" and it is also not "gas molecules". The methodologies appropriate for the definition, calculation, or measurements of the thermal conductivity of a slab or a gas are not proper with respect to the thermal conductivity of a molten slag, which in general behaves as a viscoelastic fluid. Heat conduction is through contact and contact in case of a suspension such as slag depends upon the distribution of particles and the molten fluid. Therefore, in this visualization experiment, we can see that the heat flux must depend in some form on a measure of particle distribution, as well as other important physical parameters, such as temperature gradient, deformation, velocity gradient, etc. In the next Section, we will look at a few examples of modeling the heat flux vector when some of these effects are included. We first look at the explicit approach.

\subsection{Explicit Approach}

The classical theory of heat conduction, first proposed by Fourier and later generalized by Duhamel [58] assumes that the constitutive relation for the heat flux $\mathbf{q}$ is a linear function of the temperature gradient, i.e.,:

$$
\mathbf{q}=\mathbf{K}(\theta, \mathbf{F}) \nabla \theta
$$

where $\theta$ is the temperature, $\mathbf{F}$ is the deformation gradient, and $\mathbf{K}$ is the thermal conductivity tensor. Fourier was the first person to state that heat conduction depends on the temperature gradient and not on the temperature difference between the two adjacent parts of a solid body. For an isotropic material, this reduces to the classical Fourier's law of heat conduction:

$$
\mathbf{q}=-\mathrm{k} \nabla \theta
$$


where $\mathrm{k}$ is generally assumed to be constant. For non-linear materials, a generalization of this equation is needed. For example, we may assume:

$$
\mathbf{q}=\mathbf{q}(\theta, \nabla \theta, \dot{\theta},(\nabla \theta), \ldots)
$$

where $\mathbf{q}$, is explicitly given by a function which can depend on the temperature, its gradient, its time derivative, among other variables such as velocity gradient, etc. For example, for thermo-elastic solids one can replace Equation (4.3) with:

$$
\mathbf{q}=\mathbf{q}(\theta, \nabla \theta, \mathbf{F})
$$

where for an isotopic solid material, after imposing frame-invariance [59], the above equation can be expressed as (Bowen [60], p. 98):

$$
\mathbf{q}=\mathbf{q}(\theta, \mathbf{g}, \mathbf{B})
$$

where $\mathbf{g}=\nabla \theta ; \mathbf{B}=\mathbf{F F}^{\mathrm{T}}$. Now, it can be shown that an isotropic representation of Equation (4.5) is (Bowen [60], p. 118):

$$
\mathbf{q}=\mathrm{k}_{1} \mathrm{~g}+\mathrm{k}_{2} \mathbf{B g}+\mathrm{k}_{3} \mathbf{B}^{2} \mathbf{g}
$$

where $\mathrm{k}^{\prime}$ s in general depend on the principal invariants of $\mathbf{B}$ and $\mathbf{g}$. For thermo-viscous fluids, a possible generalization of Equation (4.3) is:

$$
\mathbf{q}=\mathbf{q}(\rho, \theta, \mathbf{g}, \mathbf{D})
$$

where $\mathbf{D}=\frac{1}{2}\left(\mathbf{L}+\mathbf{L}^{\mathrm{T}}\right) ; \mathbf{L}=\operatorname{grad} \mathbf{v}$, which similarly reduces to [60]:

$$
\mathbf{q}=\beta_{1} \mathbf{g}+\beta_{2} \mathbf{D g}+\beta_{3} \mathbf{D}^{2} \mathbf{g}
$$

where $\beta \mathrm{s}$ in general depend on the principal invariants of $\mathbf{D}$ and $\mathbf{g}$. Of course, the specification (or measurement) of the response functions $\mathrm{k}_{1}, \mathrm{k}_{2}, \mathrm{k}_{3}$ or $\beta_{1}, \beta_{2}, \beta_{3}$, in the above equations, even for the simplest thermo-elastic solids or thermo-viscous fluids remains a challenge. It can also be seen that with any added complexity due to the material's structure, such as porosity, the equation for $\mathbf{q}$ will be even more complicated. Coleman and Mizel [61] suggested that for a rigid isotropic material, the heat flux vector, in general, is given by:

$$
\begin{gathered}
\mathbf{q}=\alpha \mathbf{g}+\beta(\mathbf{g} \cdot \mathbf{g}) \mathbf{g}+\gamma(\operatorname{divg}) \mathbf{g}+\delta(\text { gradg }) \mathbf{g} \text { or: } \\
\mathrm{q}_{\mathrm{m}}=\alpha \theta_{, \mathrm{m}}+\beta \theta_{, \mathrm{i}} \theta_{, \mathrm{i}} \theta_{, \mathrm{m}}+\gamma \theta_{, \mathrm{ii}} \theta_{, \mathrm{m}}+\delta \theta_{, \mathrm{mj}} \theta_{\mathrm{j}}
\end{gathered}
$$

where comma denotes differentiation with respect to $x$, and the scalar coefficients $\alpha, \beta, \gamma$, and $\delta$ depend on the temperature $\theta$. Lord and Shulman [62] indicated that in the coupled theory of thermoelasticity a general linear relationship between the heat flux and the temperature gradient should have the form:

$$
\mathbf{q}=\mathbf{b g}+\mathbf{G g} \text { Or }\left(\mathrm{q}_{\mathrm{i}}=\mathrm{b} \theta_{, \mathrm{i}}+\mathrm{G}_{\mathrm{ij}} \theta_{\mathrm{j}}\right)
$$

where $\mathrm{G}$ is a 2nd order tensor characterizing the material, and for an isotropic elastic solid, the second term disappears and the Fourier's law of conduction is obtained. However, as mentioned by Lord and Shulman [62], even with such a generalization, the energy equation still is given by a diffusion type equation and the problem that a (thermal) disturbance is felt instantaneously at positions far from the source of the disturbance remains (this is discussed in Section 4.2 where we mention the implicit theories). They then suggest that a tensorially valid linear relationship, taking into account the acceleration of the heat flow, can be given by:

$$
\mathbf{q}+\mathbf{a} \dot{\mathbf{q}}+\mathbf{A} \dot{\mathbf{q}}=b \mathbf{g}+\mathbf{G g} \text { or } \mathrm{q}_{\mathrm{i}}+\mathrm{a} \dot{\mathrm{q}}_{\mathrm{i}}+\mathrm{A}_{\mathrm{ij}} \dot{\mathrm{q}}_{\mathrm{j}}=\mathrm{b} \theta_{, \mathrm{i}}+\mathrm{G}_{\mathrm{ij}} \theta_{, j}
$$


where $a, A_{i j}, b$, and $G_{i j}$ are material properties, and for the case of an isotropic elastic solid, the equation reduces to:

$$
\mathbf{q}+\tau_{0} \dot{\mathbf{q}}=-\mathrm{kg} \text { or } \mathrm{q}_{\mathrm{i}}+\tau_{0} \dot{\mathrm{q}}_{\mathrm{i}}=-\mathrm{k} \theta, \mathrm{i}
$$

where $\tau_{0}$ is the relaxation time, representing "the time-lag needed to establish steady-state heat conduction in an element of volume when a temperature gradient is suddenly imposed on that element". Green and Lindsay [63] showed that if the constitutive equation for $\mathbf{q}$ depend on:

$$
X, \rho_{0}, \theta, \operatorname{grad} \theta, \dot{\theta}, \mathbf{F}
$$

then by imposing restrictions due to the entropy inequality, where in the linearized theory the heat conduction tensor is symmetric, then the theory is capable of predicting the "second sound" effect, if the heat flux vector is given by:

$$
\mathbf{q}=-\theta_{0}(\mathbf{b} \dot{\theta}+\mathbf{K g}) \text { or } \mathbf{q}_{\mathrm{i}}=-\theta_{0}\left(\mathbf{b} \dot{\theta}+K_{\mathrm{ij}} \theta_{, j}\right)
$$

where $\mathrm{K}_{\mathrm{ij}}$ is the thermal conductivity tensor, and $\theta_{0}$ is a constant. Liu [64] suggested that if the heat flux vector is a linear combination of the gradients of density and the internal energy, then it can be shown that $\mathbf{q}$ should be given by:

$$
\mathbf{q}=\mathrm{k}_{1} \nabla \rho+\mathrm{k}_{2} \nabla \varepsilon
$$

where $\rho$ is the density and $\varepsilon$ is the specific internal energy, $\mathrm{k}_{1}$ and $\mathrm{k}_{2}$ are functions of $\rho$ and $\varepsilon$ which can be related to the Fourier's law through

$$
\mathbf{q}=-\chi \nabla \theta
$$

where:

$$
x=-\mathrm{k}_{2} \frac{\partial \varepsilon}{\partial \theta} \geqslant 0
$$

where $\theta$ is the temperature. This indicates that in the linear theory of heat conduction for a linear viscous, i.e., Newtonian, fluid, the heat flux vector only depends on the gradient of temperature. Jaric and Golubovic [65] derived a similar expression for $\mathbf{q}$ for a non-linear heat conducting fluid where additional terms are included. Wang [66] derived a general expression for the heat flux vector for a fluid where heat convection is also important. By assuming:

$$
\mathbf{q}=\mathbf{f}(\theta, \nabla \theta, \mathbf{v}, \mathbf{L}, X)
$$

where $\mathbf{f}$ is a vector-valued function, $\theta$ temperature, $\nabla \theta$ is the gradient of temperature, $\mathbf{v}$ the velocity vector, $\mathbf{L}$ its gradient, and $X$ designates other scalar-valued thermophysical parameters. By imposing (i) the principle of frame-indifference; and (ii) the Second Law of Thermodynamics, Wang [66] showed that the above equation reduces to

$$
\mathbf{q}=-\mathbf{k} \nabla \theta
$$

where:

$$
\mathbf{k}=\varphi_{0} 1+\varphi_{1} \mathbf{D}+\varphi_{2} \mathbf{D}^{2}
$$

is called the thermal conductivity tensor, and:

$$
\varphi_{\mathrm{i}}=\varphi_{\mathrm{i}}\left[\theta, \mathrm{X}, \mathrm{J}_{\mathrm{k}}(\nabla \theta, \mathbf{D})\right](\mathrm{i}=0,1,2, \ldots \mathrm{k}=1,2, \ldots 6)
$$

where J's are the principal invariants. He also showed that if the material is at rest or has uniform motion, then $\mathbf{D}=\mathbf{0}$, and $\mathrm{J}_{\mathrm{k}}=0(\mathrm{k}=1,2, \ldots, 5)$ and Equation (4.19) reduces to:

$$
\mathbf{q}=-\varphi_{0}(\theta, X,|\nabla \theta|) \nabla \theta
$$


where $\varphi_{0}$ can now be considered to be the thermal conductivity of the material. This is a generalized form of the Fourier's law where the thermal conductivity can also be a function of the temperature gradient. Massoudi $[67,68]$ suggested that the heat flux vector $\mathbf{q}$ for a density-gradient-dependent fluid (where flowing granular materials would be a sub-class of such fluids) can be assumed to be given by:

$$
\mathbf{q}=\mathbf{q}(\theta, \mathbf{g}, \rho, \mathbf{m}, \mathbf{v}, \operatorname{grad} \mathbf{v})
$$

where $\mathbf{v}$ is the velocity, $\theta$ is the temperature, $\rho$ is the density and $\mathbf{m}=\operatorname{grad} \rho$. Then frame-indifference implies $\mathbf{q}=\mathbf{q}(\theta, \mathbf{g}, \rho, \mathbf{m}, \mathbf{D})$, where $\mathbf{D}=\frac{1}{2}\left(\mathbf{L}+\mathbf{L}^{\mathrm{T}}\right) ; \mathbf{L}=\operatorname{grad} \mathbf{v}$. This is a generalization of a case presented in Bowen ([60], p. 161) for a compressible, heat conducting viscous fluid. It is possible that the density gradient plays a role, not only in the distribution of the materials, but also in the way it influences the heat conduction. Massoudi $[67,68]$ showed that the general representation for the heat flux vector based on Equation (4.23) is given by:

$$
\begin{gathered}
\mathbf{q}=a_{1} \mathbf{g}+\mathrm{a}_{2} \mathbf{m}+\mathrm{a}_{3} D \mathbf{g}+\mathrm{a}_{4} D \mathbf{D m}+\mathrm{a}_{5} \mathbf{D}^{2} \mathbf{g}+\mathrm{a}_{6} \mathbf{D}^{2} \mathbf{m} \\
\mathbf{q}_{\mathbf{i}}=\mathbf{a}_{1} \mathbf{g}_{\mathrm{i}}+\mathbf{a}_{2} \mathbf{m}_{\mathbf{i}}+\mathbf{a}_{3} \mathbf{D}_{\mathrm{ij}} \mathbf{g}_{\mathbf{j}}+\mathbf{a}_{4} D_{\mathrm{ij}} \mathbf{m}_{\mathbf{j}}+\mathbf{a}_{5} \mathbf{D}_{\mathrm{ij}} \mathbf{g}_{\mathbf{j}}+\mathbf{a}_{6} \mathbf{D}_{\mathrm{ij}}{ }^{2} \mathbf{m}_{\mathbf{j}}
\end{gathered}
$$

where $\mathrm{a}_{1}=-\mathrm{k}$ (thermal conductivity) and $\mathrm{a}_{2}-\mathrm{a}_{6}$ are scalar functions of:

$$
\begin{gathered}
\phi(\text { or } \rho), \theta, \text { m.m, g.g, m.g, } I_{1}=\operatorname{trD}, I_{2}=\operatorname{trD}^{2}, I_{3}=\operatorname{trD} D^{3}, \\
\text { g.Dg, g. } D^{2} \text { g, m.Dm, m.D } D^{2} \text { m, g.Dm, g.D }{ }^{2}
\end{gathered}
$$

Equation (4.24) can then be re-written as:

$$
\mathbf{q}=\left(a_{1} 1+a_{3} \boldsymbol{D}+a_{5} \boldsymbol{D}^{2}\right) \nabla \theta+\left(a_{2} 1+a_{4} \boldsymbol{D}+a_{6} \boldsymbol{D}^{2}\right) \nabla \rho
$$

This equation for the heat flux vector of a thermo-viscous fluid with density gradient has a very general structure and is highly non-linear. One of the distinct non-linear phenomena that slag-type fluids exhibit is the yield stress, that is, at a certain shear rate, similar to Bingham plastic fluids, they begin to yield and the dynamic phenomenon enters into the picture. It is not uncommon to talk of "equilibrium" or "static" part of the stress tensor (corresponding to $\mathbf{D} \rightarrow 0$ ) and the "dynamic" part of the stress tensor (when $\mathbf{D} \neq 0$ ). Therefore, it seems reasonable to see the form of the heat flux vector for these two conditions or ranges. That is, in theory, it is possible to decompose the heat flux vector q into:

$$
\mathbf{q}=\mathbf{q}_{\mathrm{e}}+\mathbf{q}_{\mathrm{d}}
$$

where $\mathbf{q}_{\mathbf{e}}$ is the equilibrium part of $\mathbf{q}$ and $\mathbf{q}_{\mathbf{d}}$ is the dynamic part. For the stationary case, i.e., when $\mathbf{v}=\mathbf{0}$, or for a constant velocity field $\mathbf{v}=$ constant, we have $\mathbf{D}=\mathbf{0}$, and as a result Equation (4.26) reduces to:

$$
\mathbf{q}_{\mathrm{e}}=c_{1} \nabla \theta+c_{2} \nabla \rho
$$

If we furthermore assume:

$$
\mathrm{c}_{1}=\mathrm{c}_{1}\left(\rho, \theta,|\nabla \theta|^{2},|\nabla \rho|^{2},[\nabla \theta . \nabla \rho]\right)
$$

and:

$$
c_{2}=c_{2}\left(\rho, \theta,|\nabla \theta|^{2},|\nabla \rho|^{2},[\nabla \theta . \nabla \rho]\right)
$$

and recalling that $\rho=\rho_{s} \varphi$, where $0 \leqslant \varphi(x, t)<1$, where $\phi=0$ corresponds to a void, and $\phi=1$ means the presence of a particle, then, for non-deforming particles where $\rho_{s}=$ consant, Equation (4.28) can be re-written as:

$$
\mathbf{q}_{\mathrm{e}}=\mathrm{d}_{1}\left(\phi, \theta,|\nabla \theta|^{2},|\nabla \phi|^{2},[\nabla \theta . \nabla \phi]\right) \nabla \theta+\mathrm{d}_{2}\left(\phi, \theta,|\nabla \theta|^{2}, \mid \nabla \phi^{2},[\nabla \theta . \nabla \phi]\right) \nabla \phi
$$


If we furthermore assume that $d_{1}$ and $d_{2}$ do not depend on the gradients of the temperature and the volume fraction, then:

$$
\mathbf{q}_{\mathrm{e}}=\mathrm{e}_{1}(\phi, \theta) \nabla \theta+\mathrm{e}_{2}(\phi, \theta) \nabla \phi
$$

Note that a similar expression was given by Slattery ([10], Equation (5.3.3.7), page 274) for a class of materials whose constitutive responses were assumed to be functions of:

$$
\Lambda \equiv \Lambda(\hat{\mathrm{V}}, \theta, \nabla \hat{\mathrm{V}}, \nabla \theta)
$$

By imposing restrictions due to the second law of thermodynamics, Slattery [10] obtains:

$$
\mathbf{q}_{\mathrm{e}}=-\mathrm{k}_{(1)} \nabla \theta-\mathrm{k}_{(2)}(\nabla \hat{\mathrm{V}} \cdot \nabla \theta) \nabla \hat{\mathrm{V}}
$$

where:

$$
\begin{aligned}
& \mathrm{k}_{(1)}>0 \\
& \mathrm{k}_{(2)}>0
\end{aligned}
$$

and $\hat{V}$ is the specific volume which is related to the volume fraction. Unlike an ideal gas where there is a relationship between $\phi$ (or $\rho$ ) and $\theta$, a priori, as the constitutive relation for a perfect gas indicates, in the case of a slag we cannot assume a specific relationship, although we know that they affect each other. For many practical problems of interest, the thermal conductivity is not a function of temperature and therefore we can approximate $\mathrm{e}_{1}$ by:

$$
\mathrm{e}_{1}(\phi, \theta)=\mathrm{f}_{1}(\phi)
$$

And if we set:

$$
\mathrm{f}_{1}(\phi)=-\kappa_{\mathrm{m}}\left[1+3 \beta \phi+\hat{\beta} \phi^{2}\right]+\mathrm{o}\left(\phi^{3}\right)
$$

Equation (4.32) reduces to the equation proposed by Jeffrey [69], if $\mathrm{e}_{2}=0$. Now, with regard to $\mathrm{e}_{2}(\phi, \theta)$ there is not much information available in the literature. We can guess that the "denser" the material is, that is, the higher the value of $\phi$, the more heat will be conducted, as there are more contacts between the particles. If we approximate $e_{2}$ by expanding $e_{2}$ about $\phi=0$, holding $\theta$ fixed, we obtain:

$$
\mathrm{e}_{2}(\phi, \theta)=\mathrm{f}_{2}(\theta)+\mathrm{f}_{3}(\theta) \phi+\mathrm{f}_{4}(\theta) \phi^{2}+\ldots
$$

where, the f's can be functions of $\nabla \theta$ as well. Substituting these in Equation (4.32) we obtain:

$$
\mathbf{q}_{\mathrm{e}}=-\mathrm{K}_{\mathrm{m}}\left[1+3 \beta \phi+\hat{\beta} \phi^{2}\right] \nabla \theta+\left[\mathrm{f}_{2}(\theta)+\mathrm{f}_{3}(\theta) \phi+\mathrm{f}_{4}(\theta) \phi^{2}\right] \nabla \phi
$$

which seems to be the simplest approximation for the heat flux vector for a densely packed granular material, which is either stationary or moving with a constant velocity. It is interesting to note that as $\phi \rightarrow 0(\nabla \phi \rightarrow 0)$, we obtain the simplified equation $\mathbf{q}_{\mathrm{e}}=-\mathrm{K}_{\mathrm{m}} \nabla \theta$, where now $\mathrm{K}_{\mathrm{m}}$ is the thermal conductivity of the homogenous host material (whether the matrix or the fluid). Perhaps one can conjecture that below a certain value of $\nabla \theta$ (or $\nabla \phi$ ) there are no observable heat transfer effects, and above that value, the heat flux vector for a deforming (moving) assembly of particles should depend on appropriate constitutive parameters, including $\nabla \theta, \nabla \phi$, and $\mathbf{D}$.

For the dynamical part of the heat flux vector, we can start from:

$$
\mathbf{q}_{\mathrm{d}}=\mathrm{a}_{3} \mathbf{D g}+\mathrm{a}_{4} \mathbf{D m}+\mathrm{a}_{5} \mathbf{D}^{2} \mathbf{g}+\mathrm{a}_{6} \mathbf{D}^{2} \mathbf{m}
$$

where the a terms are scalar functions of:

$$
\begin{aligned}
& \rho, \theta, \mathbf{m} . \mathbf{m}, \mathbf{g . g}, \mathbf{m} . \mathbf{g}, \mathrm{I}_{1}=\operatorname{tr} \mathrm{D}, \mathrm{I}_{2}=\operatorname{trD}^{2}, \mathrm{I}_{3}=\operatorname{tr} \mathrm{D}^{3} \text {, } \\
& \text { g.Dg, g.D }{ }^{2} \text {, m.Dm, m.D } D^{2} \text {, g.Dm, g.D }{ }^{2} m
\end{aligned}
$$


We can obtain a simpler form of Equation (4.40) where certain higher order terms can be neglected. Let us consider the change of variables [70]:

$$
\begin{aligned}
\mathbf{g} & =\xi \overline{\mathbf{g}} \\
\mathbf{m} & =\xi \overline{\mathbf{m}} \\
\mathbf{D} & =\xi \overline{\mathbf{D}}
\end{aligned}
$$

The appropriate invariants are similarly affected, for example, $\mathrm{I}_{1}=\xi \overline{\mathrm{I}}_{1}, \mathrm{I}_{2}=\xi^{2} \overline{\mathrm{I}}_{2}, \mathrm{I}_{3}=\xi^{3} \overline{\mathrm{I}}_{3}$, and g.g $=\xi^{2} \overline{\mathbf{g}} . \overline{\mathbf{g}}$, etc. Furthermore, if we assume that $\mathrm{a}_{1}-\mathrm{a}_{6}$ are smooth analytical functions of the invariants given by:

$$
\mathrm{a}_{\mathrm{i}}=\mathrm{a}_{\mathrm{i} 0}+\xi \mathrm{a}_{\mathrm{i} 1} \mathrm{I}_{1}+\xi^{2}\left(\mathrm{a}_{\mathrm{i} 2} \mathrm{I}_{2}+\mathrm{a}_{\mathrm{i} 3} \mathbf{g} \cdot \mathbf{g}+\mathrm{a}_{\mathrm{i} 4} \mathbf{g} \cdot \mathbf{m}+\mathrm{a}_{\mathrm{i} 5} \mathbf{m} \cdot \mathbf{m}\right)+\mathrm{o}\left(\xi^{2}\right)
$$

where $i=1,2,3,4,5,6$. Thus, for example:

$$
\mathrm{a}_{1}=\mathrm{a}_{10}+\xi \mathrm{a}_{11} \mathrm{I}_{1}+\xi^{2}\left(\mathrm{a}_{12} \mathrm{I}_{2}+\mathrm{a}_{13} \mathbf{g} \cdot \mathbf{g}+\mathrm{a}_{14} \mathbf{g} \cdot \mathbf{m}+\mathrm{a}_{15} \mathbf{m} \cdot \mathbf{m}\right)+\mathrm{o}\left(\xi^{2}\right)
$$

such that $\mathrm{a}_{10}$, etc., can depend on $\theta, \phi$, etc., and $o(\xi)$ indicates:

$$
\lim \frac{o\left(\xi^{2}\right)}{\xi^{2}}=0
$$

Therefore:

$$
\mathbf{q}_{\mathbf{d}}(\xi \overline{\mathbf{g}}, \xi \overline{\mathbf{m}}, \xi \overline{\mathbf{D}})=\xi\left(a_{10} \overline{\mathbf{g}}+a_{20} \overline{\mathbf{m}}\right)+\xi^{2}\left(a_{11} I_{1} \overline{\mathbf{g}}+a_{21} I_{1} \overline{\mathbf{m}}+a_{30} \overline{\mathbf{D}} \overline{\mathbf{g}}+a_{40} \overline{\mathbf{D}} \overline{\mathbf{m}}+\mathbf{o}\left(\xi^{2}\right)\right.
$$

We can see that the first term on the RHS is the first-order approximation to $\mathbf{q}$, and the second term is the second-order correction. Re-writing this equation, we have:

$$
\mathbf{q}_{\mathrm{d}}=\mathrm{a}_{10} \nabla \theta+\mathrm{a}_{20} \nabla \rho+\mathrm{a}_{11}(\operatorname{tr} \mathbf{D}) \nabla \theta+\mathrm{a}_{21}(\operatorname{tr} \mathbf{D}) \nabla \rho+\mathrm{a}_{30} \mathbf{D} \nabla \theta+\mathrm{a}_{40} \mathbf{D} \nabla \rho
$$

If we set $\mathrm{a}_{11}=\mathrm{a}_{21}=0$, we obtain an expression similar to that obtained by Jaric and Golubovic ([65], p. 302).

Whether we use Equation (4.26) which is a very general constitutive relation for the heat flux vector for the molten slag or the more simplified expressions such as Equation (4.39) for the equilibrium part of the heat flux vector or Equation (4.46) for the dynamic part, it is clear that all of them have a more complicated form than the basic Fourier's law of conduction and therefore further experimental and computational studies are needed in order to measure and better understand the additional material properties in these non-linear constitutive equations.

\subsection{Implicit Approach}

Maxwell [71] recognized that if the classical Fourier's law of heat conduction is used in the energy equation, since one obtains a parabolic-type transport equation (diffusion type), then when the material is subjected to a thermal disturbance, the effects of it are felt instantaneously everywhere, i.e., the thermal signal propagates with infinite speed. To remedy the situation, Maxwell suggested a wave-type equation, now called the second sound, and described this phenomenon in his book, Theory of Heat ([72], p. 260):

"It follows from this result that, in calculating the temperature of point $P$, we must take into account the temperature of every other point $Q$, however distant, and however short the time may be during which the propagation of heat has been going on. Hence, in a strict sense, the influence of a heated part of the body extends to the most distant parts of the body in an incalculably short time, so that it is impossible to assign to the propagation of heat a definite velocity." 
That is, if Equation (4.2) is substituted into the equation of conservation of energy, Equation (2.4), in the absence of internal heating, for a homogenous isotropic material, one obtains the parabolic heat transport equation:

$$
\mathrm{k} \nabla^{2} \theta=\rho \mathrm{c} \frac{\partial \theta}{\partial \mathrm{t}}
$$

In order to avoid the problem of infinite speed, a generalization of the Fourier's equation [17], often referred to as the Cattaneo-Vernotte (CV) equation has been suggested:

$$
\mathbf{q}+\tau \frac{\partial \mathbf{q}}{\partial \mathbf{t}}=-\mathbf{k} \nabla \theta
$$

where $\tau$ is a positive constant. If this equation is then substituted into the energy equation, one obtains a hyperbolic-type heat transport equation:

$$
\mathrm{k} \nabla^{2} \theta=\rho \mathrm{c}\left(\frac{\partial \theta}{\partial \mathrm{t}}+\tau \frac{\partial^{2} \theta}{\partial \mathrm{t}^{2}}\right)
$$

which predicts a finite speed, $\mathrm{V}_{\mathrm{T}}=\left(\frac{\mathrm{k}}{\rho \mathrm{c} \tau}\right)^{1 / 2}$ for heat propagation. In recent years, many different non-classical thermoelasticity theories of hyperbolic-type heat transport have been developed [73,74]. Amongst the early examples of implicit constitutive relations in modern continuum mechanics one can name Truesdell's hypo-elastic [53,54] and Oldroyd's fluid [51,52] models. Morgan [75] suggested that in general, an implicit constitutive equation is a relation between a kinetic tensor, for example the stress tensor $\mathbf{T}$, and kinematic tensors, for example $\mathbf{B}$, or $\mathbf{D}$, where:

$$
\begin{aligned}
& \mathrm{G}(\mathrm{T}, \mathbf{B})=\mathbf{0} \\
& \mathbf{H}(\mathrm{T}, \mathrm{D})=\mathbf{0}
\end{aligned}
$$

The primary objective of Morgan's work was "an attempt to deductively demonstrate the existence of yield-like surfaces, or phenomena via the general principles of the mechanics of materials". Rajagopal [55] proposed an implicit relation for the stress tensor of a fluid where:

$$
\mathbf{A}(\mathbf{T}, \mathbf{D}, \theta)=\mathbf{0}
$$

By taking the time derivative of this equation and appropriately selecting terms for the resultant tensor-like coefficients, Rajagopal was able to discuss a class of constitutive relations for fluids whose viscosities depend on pressure. Similarly, the heat flux vector, in general, can be expressed as an implicit function of $\nabla \theta$ in the form [57]:

$$
\mathbf{f}(\mathbf{q}, \nabla \theta, \theta)=0
$$

where $\mathbf{f}$ is a vector valued function. Massoudi and Mehrabadi [57] showed that:

$$
\frac{\partial \mathbf{f}}{\partial \mathbf{q}} \dot{\mathbf{q}}+\frac{\partial \mathbf{f}}{\partial(\nabla \theta)}(\nabla \theta)+\frac{\partial \mathbf{f}}{\partial \theta} \dot{\theta}=0
$$

where $\frac{\partial \mathbf{f}}{\partial \mathbf{q}}$ and $\frac{\partial \mathbf{f}}{\partial(\nabla \theta)}$ are second order tensors, and $\frac{\partial \mathbf{f}}{\partial \theta}$ is a vector, and the dot denotes the material time derivative. To simplify the notation, they started with:

$$
[\mathbf{M}(\mathbf{q}, \nabla \theta, \theta)] \dot{\mathbf{q}}+[\mathbf{N}(\mathbf{q}, \nabla \theta, \theta)] \dot{\mathbf{g}}+[\mathbf{c}(\mathbf{q}, \nabla \theta, \theta)] \dot{\theta}=0
$$

where $\mathbf{M}$ and $\mathbf{N}$ are second order tensors and $\mathbf{c}$ is a vector. The above equation is a very general representation for the heat flux vector. The class of models given by Equation (4.54) is larger than 
that given by Equation (4.52) in the sense that not all models given by Equation (4.54) are included in Equation (4.52), since the terms in Equation (4.54) may not be integrable. That is, as pointed out by Massoudi and Mehrabadi (2011) [57] in Equation (4.54) it is required that the heat flux vector and the temperature gradient have time derivatives, whereas no such restrictions are required in Equation (4.52).

Fox [76] derived an implicit constitutive relation for the heat flux vector $\mathrm{q}_{\mathrm{i}}$, where:

$$
\dot{\mathbf{q}}=\mathbf{f}(\mathbf{F}, \mathbf{D}, \mathbf{W}, \mathbf{q}, \theta, \nabla \theta)
$$

where $\mathbf{F}, \mathbf{D}, \mathbf{W}, \mathbf{q}, \theta, \nabla \theta$ are the deformation gradient, the symmetric part of the velocity gradient, the skew-symmetric part of the velocity gradient, the heat flux vector, the temperature, and the temperature gradient, respectively. The dot denotes $\mathrm{d} / \mathrm{dt}$ (the material time derivative) given by $\frac{\mathrm{d}(.)}{\mathrm{dt}}=\frac{\partial(.)}{\partial \mathrm{t}}+[\operatorname{grad}().] \mathbf{v}$. Imposing the principle of frame-indifference and recalling that $\mathbf{\Omega}=-\mathbf{Q Q}^{\mathrm{T}}$ where $\mathbf{Q}$ is a time-dependent rotation tensor, reduces Equation (4.55) to:

$$
\stackrel{\circ}{\mathbf{q}}=\dot{\mathbf{q}}-\mathbf{W q}=\mathbf{h}(\mathbf{F}, \mathbf{D}, \mathbf{q}, \theta, \nabla \theta)
$$

which for isotopic materials becomes:

$$
\stackrel{\circ}{\mathbf{q}}=\dot{\mathbf{q}}-\mathbf{W q}=\mathbf{h}(\mathbf{B}, \mathbf{D}, \mathbf{q}, \theta, \nabla \theta)
$$

where $\mathbf{B}=\mathbf{F F}^{\mathrm{T}}$ and $\mathbf{D}=\frac{1}{2}\left[\operatorname{grad} \mathbf{v}+(\operatorname{grad} \mathbf{v})^{\mathrm{T}}\right]$. In order to simplify this relationship further, Fox (1969) [76] assumed that there is no dependence on B, and suggested the following relation for $\stackrel{\circ}{\mathbf{q}}$.

$$
\stackrel{\circ}{\mathbf{q}}=\dot{\mathbf{q}}-\mathbf{W q}=\alpha \mathbf{q}+\beta \nabla \theta
$$

where $\alpha$ and $\beta$ are functions of $\theta$ and the principal invariants q.q. q. $\nabla \theta, \nabla \theta \cdot \nabla \theta$. By choosing $\alpha=-\frac{1}{\tau}$ and $\beta=\kappa \alpha$, an equation similar to Maxwell-Cattaneo model is obtained [77]:

$$
\tau(\dot{\mathbf{q}}-\mathbf{W q})=-\mathbf{q}-\mathrm{k} \nabla \theta
$$

Massoudi and Mehrabadi [57] starting with

$$
\stackrel{\circ}{\mathbf{q}}=\dot{\mathbf{q}}-\mathbf{W q}=\mathbf{h}(\mathbf{B}, \mathbf{q}, \theta, \nabla \theta)
$$

and defining $\mathbf{g}=\nabla \theta$, showed that, for an isotropic representation for $\stackrel{\circ}{\mathbf{q}}$, the generators for Equation $(4.60)$ are $[78,79]$ :

$$
\mathbf{B}, \mathbf{B}^{2}, \mathbf{q}, \mathbf{g}
$$

and the invariants associated with Equation (4.61) are:

$$
\begin{gathered}
\mathrm{B} \rightarrow \operatorname{trB}, \operatorname{trB}^{2}, \operatorname{trB}^{3} \\
\mathrm{q} \rightarrow \mathrm{q} \cdot \mathrm{q} \\
\mathrm{g} \rightarrow \mathrm{g} \cdot \mathrm{g} \\
\mathrm{q}, \mathrm{g} \rightarrow \mathrm{q} \cdot \mathrm{g} \\
\mathrm{q}, \mathrm{B} \rightarrow \mathrm{q.Bq}, \mathrm{q} \cdot \mathrm{B}^{2} \mathrm{q} \\
\mathrm{g}, \mathrm{B} \rightarrow \mathrm{g.Bg}, \mathrm{g} . \mathrm{B}^{2} \mathrm{~g} \\
\mathrm{B,q}, \mathrm{g} \rightarrow \mathrm{q} \cdot \mathrm{Bg}, \mathrm{q} \cdot \mathrm{B}^{2} \mathrm{~g}
\end{gathered}
$$


They showed that using Equations (4.61) and (4.62), a general implicit representation for the heat flux vector is:

$$
\stackrel{\circ}{\mathbf{q}}=\dot{\mathbf{q}}-\mathbf{W q}=\mathrm{a}_{1} \mathbf{g}+\mathrm{a}_{2} \mathbf{q}+\mathrm{a}_{3} \mathbf{B g}+\mathrm{a}_{4} \mathbf{B q}+\mathrm{a}_{5} \mathbf{B}^{2} \mathbf{g}+\mathrm{a}_{6} \mathbf{B}^{2} \mathbf{q}
$$

where $a_{1}-a_{6}$ are scalar functions of the appropriate principal invariants given on the right hand side of Equations (4.62) and $\mathbf{B}=\mathbf{F F}^{\mathrm{T}}, \mathbf{W}=\frac{1}{2}\left[\mathbf{L}-\mathbf{L}^{T}\right]$. Now if all a's are set to zero, except $\mathrm{a}_{1}$ and $\mathrm{a}_{2}$ (corresponding for example to a homogeneous deformation where $\operatorname{det} \mathbf{F}=1$ ), we have:

$$
\stackrel{\circ}{\mathbf{q}}=\dot{\mathbf{q}}-\mathbf{W q}=\mathrm{b}_{1} \mathbf{g}+\mathrm{b}_{2} \mathbf{q}
$$

This is identical to Equation (5.17) of Fox [76]. Thus, in a sense Equation (4.63) is a generalization of Fox (1969) [76] who had suggested that an equation of the type:

$$
\tau \frac{\partial \mathbf{q}}{\partial \mathrm{t}}+\mathbf{q}=-k g r a d \theta
$$

where according to Chester [80] the relaxation time can be estimated as $\tau=\frac{3 k}{S^{2} C}$, where $S$ is a sound velocity and $\mathrm{C}$ is a specific heat of the solid, can potentially overcome the problem of infinite speed. McTaggart and Lindsay [77] developed a general law of heat conduction using ideas of Maxwell, Cattaneo, and Fox, and named their model MCF, where the equation for the heat flux vector is given by:

$$
\tau(\dot{\mathbf{q}}-\mathbf{W q})=-\mathbf{q}-k \mathbf{g} \text { or } \tau\left(\dot{\mathrm{q}}_{\mathrm{i}}-\omega_{\mathrm{ij}} \mathrm{q}_{\mathrm{j}}\right)=-\mathrm{q}_{\mathrm{i}}-\mathrm{k} \theta_{, \mathrm{i}}
$$

where $\omega_{i j}$ is the vorticity, $\mathrm{k}$ the thermal conductivity, and $\tau$ the thermal relaxation time. If $\omega_{i j}=0$, then this equation reduces to Cattaneo model, and when $\tau=0$, it becomes the Fourier's law.

For a non-linear viscous fluid, Massoudi and Mehrabadi [57] suggested:

$$
\stackrel{\circ}{\mathbf{q}}=\mathbf{f}(\rho, \theta, \mathbf{g}, \mathbf{m}, \mathbf{q}, \mathbf{D})
$$

where $\mathbf{g}=\operatorname{grad} \theta, \mathbf{m}=\operatorname{grad} \rho$ and $\mathbf{q}$, are objective vectors and $\mathbf{D}$ is the symmetric part of the velocity gradient (an objective second rank tensor). It was assumed that $\mathbf{m}$ (the density gradient, related to the gradient of volume fraction which is related to porosity) is a measure of particle distribution. According to the representation theorems, the generators are:

$$
\text { g, m, q, Dg, Dm, Dq, } D^{2} \mathbf{g}, \mathbf{D}^{2} \mathbf{m}, \text { and } \mathbf{D}^{2} \mathbf{q}
$$

An isotropic vector valued function based on these generators can be obtained:

$$
\stackrel{\circ}{\mathbf{q}}=\alpha_{1} \mathbf{g}+\alpha_{2} \mathbf{m}+\alpha_{3} \mathbf{q}+\alpha_{4} \mathbf{D g}+\alpha_{5} \mathbf{D m}+\alpha_{6} \mathbf{D q}+\alpha_{7} \mathbf{D}^{2} \mathbf{g}+\alpha_{8} \mathbf{D}^{2} \mathbf{m}+\alpha_{9} \mathbf{D}^{2} \mathbf{q}
$$

where the $\alpha / s$ are functions of the appropriate principal invariants, depending on the generators listed in Equation (4.68). This is a very general implicit constitutive relation for the heat flux vector. While Equation (15) is appropriate for an isotopic non-linear thermo-elastic material, Equation (4.69) is for a density-gradient-type thermo-viscous fluid. As with all implicit constitutive relations, the numerical schemes to solve these equations are much more complicated, as the governing equations and the constitutive equations are to be solved simultaneously. Furthermore, the higher order terms in Equation (4.69) require additional boundary conditions.

Since slag, in general, behaves as a viscoelastic fluid, perhaps both Equations (4.63) and (4.69) are needed. In the final section of this paper, we present a few remarks about modeling issues related to the heat flux vector for slag. 


\section{Concluding Remarks}

Although there are many studies related to the modeling of thermal conductivity of suspensions, polymers, porous media, etc., in this brief review we have limited our attention to those cases which specifically have addressed modeling of a fluid-like slag. Obviously, there are some similarities since slag is also a suspension with a measure of porosity (particle concentration).

As mentioned at the end of Section 1, in general, the modeling efforts have been directed to the formulation of the thermal conductivity of slag, mostly based on experimental data, and this approach has certain limitations. One such limitation is that the form of the heat flux vector assumed in almost all of these studies is that of the Fourier's heat conduction and as shown by many researchers, for complex materials, this is not valid in general and alternative formulations are needed. In Section 2, we reviewed briefly some of the studies which have provided expressions for the thermal conductivity of slag. In Sections 3 and 4 we attempted to provide a framework for modeling of the slag as a viscoelastic fluid, where explicit and implicit schemes can be used to obtain or derive constitutive relations for the heat flux vector. We did not discuss modeling of the thermal conductivity in these two schemes. This is left for future studies, as we can see that there are, in addition to thermal conductivity, other material parameters which appear in the non-linear constitutive relations for the heat flux vector and all these material parameters, in a sense, have to be studied and measured experimentally.

If we model the heat flux vector for the slag using the explicit approach, then we can use, as a general expression, the results of Massoudi $[67,68]$ who showed that the general representation for the heat flux vector based on Equation (4.23) is given by:

$$
\mathbf{q}=\mathrm{a}_{1} \mathbf{g}+\mathrm{a}_{2} \mathbf{m}+\mathrm{a}_{3} \mathbf{D g}+\mathrm{a}_{4} \mathbf{D m}+\mathrm{a}_{5} \mathbf{D}^{2} \mathbf{g}+\mathrm{a}_{6} \mathbf{D}^{2} \mathbf{m}
$$

where $a_{1}=-k$ (thermal conductivity) and $a_{2}-a_{6}$ are scalar functions of: $\phi$ (or $\rho$ ) , $\theta, \mathbf{m} . \mathbf{m}, \mathbf{g . g}, \mathbf{m} . \mathbf{g}$, $\mathrm{I}_{1}=\operatorname{trD}, \mathrm{I}_{2}=\operatorname{tr} \mathbf{D}^{2}, \mathrm{I}_{3}=\operatorname{tr} \mathbf{D}^{3}$, g.Dg, g. $\mathbf{D}^{2} \mathbf{g}, \mathbf{m} \cdot \mathbf{D m}, \mathbf{m} \cdot \mathbf{D}^{2} \mathbf{m}$, g.Dm, g. $\mathbf{D}^{2} \mathbf{m}$.

Equation (4.24) can be re-written as:

$$
\mathbf{q}=\left(a_{1} \mathbf{1}+a_{3} \boldsymbol{D}+a_{5} \boldsymbol{D}^{2}\right) \nabla \theta+\left(a_{2} 1+a_{4} \boldsymbol{D}+a_{6} \boldsymbol{D}^{2}\right) \nabla \rho
$$

This equation for the heat flux vector of a thermos-viscous fluid with density gradient has a very general structure and is highly non-linear. In theory, it is possible to decompose the heat flux vector $\mathbf{q}$ into: $\mathbf{q}=\mathbf{q}_{\mathrm{e}}+\mathbf{q}_{\mathrm{d}}$ where $\mathbf{q}_{\mathrm{e}}$ is the equilibrium part of $\mathbf{q}$ and $\mathbf{q}_{\mathrm{d}}$ is the dynamic part.

If we use an implicit scheme, then a general constitutive relation for the elastic part of the heat flux vector for the slag behaving as a viscoelastic fluid is [57]:

$$
\stackrel{\circ}{\mathbf{q}}=\dot{\mathbf{q}}-\mathbf{W q}=\mathrm{a}_{1} \mathbf{g}+\mathrm{a}_{2} \mathbf{q}+\mathrm{a}_{3} \mathbf{B g}+\mathrm{a}_{4} \mathbf{B} \mathbf{q}+\mathrm{a}_{5} \mathbf{B}^{2} \mathbf{g}+\mathrm{a}_{6} \mathbf{B}^{2} \mathbf{q}
$$

where $\mathrm{a}_{1}-\mathrm{a}_{6}$ are scalar functions of the appropriate principal invariants given on the right hand side of Equations (4.62) and $\mathbf{B}=\mathbf{F F}^{\mathrm{T}}, \mathbf{W}=\frac{1}{2}\left[\mathbf{L}-\mathbf{L}^{T}\right]$. Now if all a's are set to zero, except $\mathrm{a}_{1}$ and $\mathrm{a}_{2}$ (corresponding for example to a homogeneous deformation where $\operatorname{det} F=1$ ), we have:

$$
\stackrel{\circ}{\mathbf{q}}=\dot{\mathbf{q}}-\mathbf{W q}=\mathrm{b}_{1} \mathbf{g}+\mathrm{b}_{2} \mathbf{q}
$$

For the viscous part of the slag, we can use the results of Massoudi and Mehrabadi [57] who suggested an isotropic vector valued function for the heat flux:

$$
\stackrel{\circ}{\mathbf{q}}=\alpha_{1} \mathbf{g}+\alpha_{2} \mathbf{m}+\alpha_{3} \mathbf{q}+\alpha_{4} \mathbf{D g}+\alpha_{5} \mathbf{D m}+\alpha_{6} \mathbf{D q}+\alpha_{7} \mathbf{D}^{2} \mathbf{g}+\alpha_{8} \mathbf{D}^{2} \mathbf{m}+\alpha_{9} \mathbf{D}^{2} \mathbf{q}
$$

where $\mathbf{g}=\operatorname{grad} \theta, \mathbf{m}=\operatorname{grad} \rho$ and the $\alpha / \mathrm{s}$ are functions of the appropriate principal invariants, depending on the generators listed in Equation (4.68). This is a very general implicit constitutive 
relation for the heat flux vector. While Equation (4.15) is appropriate for an isotopic non-linear thermo-elastic material, Equation (4.69) is for a density-gradient-type thermo-viscous fluid. As with all implicit constitutive relations, such as Oldroyd-type fluids, the numerical schemes to solve these equations are much more complicated, as the governing equations and the constitutive equations are to be solved simultaneously. Furthermore, the higher order terms in Equation (4.69) require additional boundary conditions.

In this brief review we have not addressed the important question of how the material parameters appearing Equations (4.26) and (4.69) can be measured or can be calibrated against the existing experimental data. This issue, as important as it is, is beyond the scope of our study. However, a recent study by Miao and Massoudi [81], where a simplified version of Equation (4.26) was used to study the heat transfer to a slurry, indicates that indeed the non-linear terms in the heat flux vector, which also appear in the expression for the thermal conductivity, significantly influence the heat transfer characteristic of the fluid. The discussion of the constitutive modeling of the heat flux vector for slag is from a theoretical perspective.

Acknowledgments: The auhtors are grateful to the reivewers for helpful comments.

Author Contributions: Mehrdad Massoudi is the primary author for this paper. Jeongho Kim wrote Section 3 of the paper. Mehrdad Massoudi wrote most of Sections 1, 2, 4 and 5 with some help from Ping Wang. All authors contributed in the discussion, development of the ideas and the implementation of the ideas, and to some extent in the writing and editing of the manuscript.

Conflicts of Interest: The authors declare no conflict of interest.

\section{References}

1. Massoudi, M.; Wang, P. Slag Behavior in Gasifiers. Part II: Constitutive Modeling of Slag. Energies 2013, 6, 807-838. [CrossRef]

2. $\quad$ Erickson, T.A.; Allan, S.E.; McCollor, D.P.; Hurley, J.P.; Srinivasachar, S.; Kang, S.G.; Baker, J.E.; Morgan, M.E.; Johnson, S.A.; Borio, R. Modeling of fouling and slagging in coal-fired utility boilers. Fuel Process. Technol. 1995, 44, 155-171. [CrossRef]

3. Vorres, K.S.; Greenberg, S.; Poeppel, R. Viscosity of synthetic coal ash slags. ACS Symp. Ser. 1986, 301, 156-169.

4. Lawn, C.J. Principles of Combustion Engineering for Boilers; Academic Press: London, UK, 1987.

5. Jak, E.; Saulov, D.; Kondratiev, A.; Hayes, P.C. Prediction of phase equilibria and viscosity in complex coal ash slag systems. Abstr. Pap. Am Chem. Soc. 2004, 227, U1079.

6. Groen, J.C.; Brooker, D.D.; Welch, P.J.; Oh, M.S. Gasification slag rheology and crystallization in titanium-rich, iron-calcium-aluminosilicate glasses. Fuel Process. Technol. 1998, 56, 103-127. [CrossRef]

7. Zbogar, A.; Frandsen, F.J.; Jensen, P.A.; Glarborg, P. Heat transfer in ash deposits: A modelling tool-box. Prog. Energy Combust. Sci. 2005, 31, 371-421. [CrossRef]

8. Zbogar, A.; Frandsen, F.J.; Jensen, P.A.; Glarborg, P. Shedding of ash deposits. Prog. Energy Combust. Sci. 2009, 35, 31-56. [CrossRef]

9. Massoudi, M.; Wang, P. A Brief Review of Viscosity Models for Slag in Coal Gasification. Available online: http://www.osti.gov/servlets/purl/1036735/ (accessed on 27 December 2015).

10. Slattery, J.C. Advanced Transport Phenomena; Cambridge University Press: Cambridge, UK, 1999.

11. Liu, I.S. Continuum Mechanics; Springer-Verlag: Berlin, German, 2002.

12. Muller, I. On entropy inequality. Arch. Ration. Mech. Anal. 1967, 26, 118-141. [CrossRef]

13. Ziegler, H. An Introduction to Thermomechanics; 2nd Revised ed.; North-Holland Publishing Company: Amsterdam, The Netherland, 1983.

14. Fourier, J. The Analytical Theory of Heat (Dover Books on Physics); Dover Publications: New York, NY, USA, 2003.

15. Kaviany, M. Principles of Heat Transfer in Porous Media, 2nd ed.; Springer-Verlag: New York, NY, USA, 1995.

16. Petroski, H.J. Departures from fouriers law. ZAMP 1975, 26, 119-124. [CrossRef]

17. Narasimhan, T.N. Fourier's heat conduction equation: History, influence, and connections. Rev. Geophys. 1999, 37, 151-172. [CrossRef] 
18. Winterton, R.H.S. Early study of heat transfer: Newton and Fourier. Heat Transf. Eng. 2001, $22,3-11$. [CrossRef]

19. Russell, H. Principles of heat flow in porous insulators. J. Am. Ceram. Soc. 1935, 18, 1-5. [CrossRef]

20. Leach, A. The thermal conductivity of foams. I. Models for heat conduction. J. Phys. D 1993, 26, 733-739. [CrossRef]

21. Kingery, W. Heat-Conductivity Processes in Glass. J. Am. Ceram. Soc. 1961, 44, 302-304. [CrossRef]

22. Parker, W.; Jenkins, R.; Butler, C.; Abbott, G. Flash method of determining thermal diffusivity, heat capacity, and thermal conductivity. J. Appl. Phys. 1961, 32, 1679-1684. [CrossRef]

23. Brailsford, A.; Major, K. The thermal conductivity of aggregates of several phases, including porous materials. Br. J. Appl. Phys. 1964, 15, 313-319. [CrossRef]

24. Susa, M.; Nagata, K.; Goto, K. Temperatuere-Dependence of Thermal-Conductivity of Solid and Liquid Slags; Transactions of the Iron and Steel Institute of Japan: Tokyo, Japan, 1982; p. B42.

25. Taylor, R.; Mills, K.C. Thermal conductivity of slags used in electroslag remelting. Arch. Eisenhuettenwesen 1982, 53, 55-63.

26. Mills, K. Heat Transfer and Thermal Conductivity of Coal Slags; American Chemical Society: Washington, DC, USA, 1986; pp. 257-276.

27. Fine, H.A.; Engh, T.; Elliott, J.F. Measurement of the thermal diffusivity of liquid oxides and metallurgical slags. Metall. Trans. B 1976, 7, 277-285. [CrossRef]

28. Odawara, O.; Okada, I.; Kawamura, K. Measurement of the thermal diffusivity of HTS (a mixture of molten sodium nitrate-potassium nitrate-sodium nitrite; 7-44-49 mole\%) by optical interferometry. J. Chem. Eng. Data 1977, 22, 222-225. [CrossRef]

29. Chekhovskoi, V.Y.; Ulashchik, A. Thermal conductivity of slags in the solid and liquid states. High Temp. Mater. Process. 1987, 25, 672-676.

30. Botterill, J.; Salway, A.; Teoman, Y. The effective thermal conductivity of high temperature particulate beds-I. Experimental determination. Int. J. Heat Mass Transf. 1989, 32, 585-593. [CrossRef]

31. Mikrovas, A.C.; Argyropoulos, S. Heat transfer characteristics of molten slags. Ironmak. Steelmak. 1991, 18, 169-181.

32. Susa, M.; Li, F.; Nagata, K. Thermal conductivity, thermal diffusivity and specific heat of slags containing iron oxides. Ironmak. Steelmak. 1993, 20, 201-206.

33. Larsen, E.S. The Microscopic Determination of the Nonopaque Minerals; US Government Printing Office: Washington, DC, USA, 1921.

34. Krupiczka, R. Analysis of thermal conductivity in granular materials. Int. Chem. Eng. 1967, 7, $122-144$.

35. Hadley, G. Thermal conductivity of packed metal powders. Int. J. Heat Mass Transf. 1986, 29, 909-920. [CrossRef]

36. Bauer, T. A general analytical approach toward the thermal conductivity of porous media. Int. J. Heat Mass Transf. 1993, 36, 4181-4191. [CrossRef]

37. Gupta, R.; Wall, T.; Baxter, L. Impact of Mineral Impurities in Solid Fuel Combustion; Springer Science \& Business Media: New York, NY, USA, 1999.

38. McAdams, W.H. Heat Transmission, 3rd ed.; McGraw-Hill: New York, NY, USA, 1954.

39. Laubitz, M. Thermal conductivity of powders. Can. J. Phys. 1959, 37, 798-808. [CrossRef]

40. Rezaei, H.R.; Gupta, R.P.; Bryant, G.W.; Hart, J.T.; Liu, G.S.; Bailey, C.W.; Wall, T.F.; Miyamae, S.; Makino, K.; Endo, Y. Thermal conductivity of coal ash and slags and models used. Fuel 2000, 79, 1697-1710. [CrossRef]

41. Boow, J.; Goard, P. Fireside deposits and their effect on heat transfer in apulverized-fuel-fired boiler. J. Inst. Fuel 1969, 42, 412-419.

42. Quested, P.N.; Monaghan, B.J. The measurement of thermophysical properties of molten slags and fluxes. High Temp. Mater. Process. 2001, 20, 219-234. [CrossRef]

43. Kang, Y.; Morita, K. Thermal conductivity of the $\mathrm{CaO}-\mathrm{Al}_{2} \mathrm{O}_{3}-\mathrm{SiO}_{2}$ system. ISIJ Int. 2006, 46, 420-426. [CrossRef]

44. Sun, S.Y.; Tran, T.; Wright, S. Thermal properties of molten slags. In Proceedings of the 1st Australia-China-Japan Symposium on Iron and Steelmaking, Shenyang, China, 2006; pp. 85-89. 
45. Susa, M.; Watanabe, M.; Ozawa, S.; Endo, R. Thermal conductivity of $\mathrm{CaO}-\mathrm{SiO}_{2}-\mathrm{Al}_{2} \mathrm{O}_{3}$ glassy slags: Its dependence on molar ratios of $\mathrm{Al}_{2} \mathrm{O}_{3} / \mathrm{CaO}$ and $\mathrm{SiO}_{2} / \mathrm{Al}_{2} \mathrm{O}_{3}$. Ironmak. Steelmak. 2007, 34, 124-130. [CrossRef]

46. Ni, J.; Zhou, Z.; Yu, G.; Liang, Q.; Wang, F. Molten slag flow and phase transformation behaviors in a slagging entrained-flow coal gasifier. Ind. Eng. Chem. Res. 2010, 49, 12302-12310. [CrossRef]

47. Bird, R.; Stewart, W.; Lightfoot, E. Transport Phenomena; John Wiley: New York, NY, USA, 1960.

48. Mills, K.C.; Rhine, J.M. The measurement and estimation of the physical properties of slags formed during coal gasification: 1. Properties relevant to fluid flow. Fuel 1989, 68, 193-200. [CrossRef]

49. Brackbill, J.; Kothe, D.B.; Zemach, C. A continuum method for modeling surface tension. J. Comput. Phys. 1992, 100, 335-354. [CrossRef]

50. Hasegawa, H.; Ohta, H.; Shibata, H.; Waseda, Y. Recent Development in the Investigation on Thermal Conductivity of Silicate Melts. High Temp. Mater. Process. 2012, 31, 491-499. [CrossRef]

51. Oldroyd, J.G. On the formulation of rheological equations of state. Proc. R. Soc. Lond. A 1950, 200, 523-541. [CrossRef]

52. Oldroyd, J.G. An approach to non-newtonian fluid-mechanics. J. Non-Newton. Fluid Mech. 1984, 14, 9-46. [CrossRef]

53. Truesdell, C. Hypo-elasticity. J. Ration. Mech. Anal. 1955, 4, 83-131. [CrossRef]

54. Truesdell, C. Continuum Mechanics: The Mechanical Foundations of Elasticity and Fluid Dynamics; Gordon and Breach: New York, NY, USA, 1966.

55. Rajagopal, K.R. On implicit constitutive theories for fluids. J. Fluid Mech. 2006, 550, 243-249. [CrossRef]

56. Massoudi, M.; Mehrabadi, M.M. Implicit Continuum Mechanics Approach to Heat Conduction in Granular Materials. Ind. Eng. Chem. Res. 2010, 49, 5215-5221. [CrossRef]

57. Massoudi, M.; Mehrabadi, M.M. Implicit constitutive relations in thermoelasticity. Int. J. Non-Linear Mech. 2011, 46, 286-290. [CrossRef]

58. Truesdell, C. Rational Thermodynamics, 2nd ed.; Springer-Verlag: New York, NY, USA, 1984.

59. Truesdell, C.; Noll, W. The Non-Linear Field Theories of Mechanics; Springer-Verlag: New York, NY, USA, 1992.

60. Bowen, R.M. Introduction to Continuum Mechanics for Engineers; Plenum Press: New York, NY, USA, 1989.

61. Coleman, B.D.; Mizel, V.J. Thermodynamics and departures from fouriers law of heat conduction. Arch. Ration. Mech. Anal. 1963, 13, 245-261. [CrossRef]

62. Lord, H.W.; Shulman, Y. A generalized dynamical theory of thermoelasticity. J. Mech. Phys. Solids 1967, 15, 299-309. [CrossRef]

63. Green, A.E.; Lindsay, K.A. Thermoelasticity. J. Elast. 1972, 2, 1-7. [CrossRef]

64. Liu, I.S. On fourier law of heat-conduction. Contin. Mech. Thermodyn. 1990, 2, 301-305. [CrossRef]

65. Jaric, J.; Golubovic, Z. Fourier's law of heat conduction in a nonlinear fluid. J. Therm. Stress. 1999, 22, $293-303$.

66. Wang, L.Q. Vector-field theory of heat flux in convective heat transfer. Nonlinear Anal. Theory Methods Appl. 2001, 47, 5009-5020. [CrossRef]

67. Massoudi, M. On the heat flux vector for flowing granular materials-Part I: Effective thermal conductivity and background. Math. Methods Appl. Sci. 2006, 29, 1585-1598. [CrossRef]

68. Massoudi, M. On the heat flux vector for flowing granular materials-PART II: Derivation and special cases. Math. Methods Appl. Sci. 2006, 29, 1599-1613. [CrossRef]

69. Jeffrey, D.J. Conduction through a random suspension of spheres. Proc. R. Soc. Lond. Ser. Math. Phys. Sci. 1973, 335, 355-367. [CrossRef]

70. Greenberg, M.D. Foundations of Applied Mathematics; Prentice-Hall, Inc.: Englewood Cliffs, NJ, USA, 1978.

71. Maxwell, J.C. On the dynamical theory of gases. Phil. Trans. R. Soc. Lond. 1867, 157, 49-88. [CrossRef]

72. Maxwell, J.C. Theory of Heat; Dover Publications Inc.: New York, NY, USA, 2001.

73. Chandrasekharaiah, D.S. Thermoelasticity with second sound: A review. Appl. Mech. Rev. 1986, 39, 355-376. [CrossRef]

74. Chandrasekharaiah, D.S. Hyperbolic thermoelasticity: A review of recent literature. Appl. Mech. Rev. 1998, 51, 705-729. [CrossRef]

75. Morgan, A.J.A. Some properties of media by constitutive equations in implicit form. Int. J. Eng. Sci. 1966, 4, 155-178. [CrossRef]

76. Fox, N. Generalised thermoelasticity. Int. J. Eng. Sci. 1969, 7, 437-445. [CrossRef]

77. McTaggart, C.L.; Lindsay, K.A. Nonclassical effects in the benard-problem. Siam J. Appl. Math. 1985, 45, 70-92. [CrossRef] 
78. Spencer, A.J.M. Theory of Invariants. In Continuum Physics; Eringen, A.C., Ed.; Academic Press: New York, NY, USA, 1971.

79. Zheng, Q.S. Theory of representations for tensor functions-A unified invariant approach to constitutive equations. Appl. Mech. Rev. 1994, 47, 545-587. [CrossRef]

80. Chester, M. Second sound in solids. Phys. Rev. 1963, 131. [CrossRef]

81. Miao, L.; Massoudi, M. Effects of Shear Dependent Viscosity and Variable Thermal Conductivity on the Flow and Heat Transfer in a Slurry. Energies 2015, 8, 11546-11574. [CrossRef]

(c) 2016 by the authors; licensee MDPI, Basel, Switzerland. This article is an open access article distributed under the terms and conditions of the Creative Commons by Attribution (CC-BY) license (http:/ / creativecommons.org/licenses/by/4.0/). 